\title{
Original Articles \\ Microalbuminuria Represents a Feature of Advanced Renal Disease in Patients with Sickle Cell Haemoglobinopathy
}

\author{
C.K. Ackoundou-N'Guessan, M. W. Tia, D. A. Lagou, A. Cissoko, C. M. Guei and \\ D. A. Gnionsahe \\ Nephrology, Hypertension and Dialysis Unit, Department of Medicine, Yopougon Teaching Hospital, Abidjan, \\ Ivory Coast
}

\section{SUMMARY}

Chronic renal failure (CRF) occurring in sickle cell disease has a dismal outcome. The systematic screening for microalbuminuria represents the touchstone to prevent CRF in patients with diabetes mellitus. Microalbuminuria has also been demonstrated in patients with sickle cell disease. Whether this has the same prognostic significance as it does in diabetes mellitus has never been clearly stated. The purpose of the present study was to determine the prevalence of microalbuminuria and to establish the clinical significance of microalbuminuria in patients with sickle cell disease. Patients with sickle cell disease of both sexes and all ages were consecutively recruited at the haematology outpatient clinic of the Yopougon Teaching Hospital, Abidjan, Ivory Coast. in a prospective study from July to September 2004. In each patient characteristics such as age, gender, ethnic group, weight, height, blood pressure, type of haemoglobinopathy, glomerular filtration rate, complications related to the disease and current treatment were collected. Microalbuminuria was assessed in all the patients. Statistical analysis was performed to identify factors related to microalbuminuria. The prevalence of microalbuminuria was $17.3 \%$ in our study population. Glomerular filtration rate was significantly lower in the microalbuminuric group than in the normoalbuminuric group both on univariate analysis $(p<0.01)$ and on multivariate analysis $(O R=1.074)$ CI 95\% [1.020 1.136])

All Correspondence to

Dr CK Ackoundou-N'Guessan

Nephrology, Hypertension and Dialysis Unit,

Yopougon Teaching Hospital,

PO BOX 632, Abidjan 21, Ivory Coast. $(p<0.01)$. Height was significantly lower in the microalbuminuric group than in the normoalbuminuric group both on univariate analysis $(p=0.05)$ and on multivariate analysis $(O R=1.029$ CI 95\% [ 1.0031 .056$])(p<0.05)$. Anaemia was more prevalent in the microalbuminuric group than in the normoalbuminuric group $(p<0.05)$ on univariate analysis but not on multivariate analysis. No relationship has been found between microabuminuria and age, as well as with disease duration and body mass index. Microalbuminuria in sickle cell disease patients represents a feature of more advanced disease as it is significantly related to low glomerular filtration rate. The high prevalence of anaemia in the microalbuminuric patients corroborates the depressed renal function. The role of short height in the promotion of microalbuminuria is unclear.

Keywords: Sickle cell disease, microabuminuria, glomerular filtration rate, height, anaemia.

\section{INTRODUCTION}

Microalbuminuria (MA) has been reported in many settings, including diabetic nephropathy and the general population. In the general population, it has been demonstrated as a marker of generalized vascular disease. In diabetics, it is an early marker of diabetic nephropathy [1]. Microalbuminuria has also been reported in the setting of sickle cell disease (SCD) [2]. Its clinical significance remains unclear. Chronic renal failure has been reported to develop in $4.2 \%$ of 725 patients with sickle cell anaemia and in $2.4 \%$ of 209 patients with $\mathrm{HbSC}$ in a 25 -yearlong prospective study [3]. Kidney failure occurring 


\section{Sickle Cell Glomerulopathy}

in patients with sickle cell disease has a dismal outcome. The survival time for patients with SCD after the diagnosis of CRF, despite dialysis, was 4 years, and the median age at the time of death was 27 years. This may be related in part to anaemia that remains an important factor of mortality and morbidity. Indeed, anaemia in SCD cannot be fully corrected because the correction of anaemia represents a promoting factor for vasoocclusive crisis. Moreover, kidney transplantation has not always been a viable option to dialysis since recurrence in the kidney graft appears to be a common feature after transplantation. Predictors of chronic renal failure in subjects with sickle cell disease are hypertension, proteinuria, hematuria, increasingly severe anaemia, the nephrotic syndrome, inheritance of the Bantu or the Central African Republic beta globin gene cluster haplotype [3]. Whether microalbuminuria is also a predictor of chronic renal failure, as it does in diabetes, has never been clearly stated. The aim of the present study was to determine the prevalence of microalbuminuria and to establish the clinical significance of microalbuminuria in patients with sickle cell disease in Ivory Coast.

\section{PATIENTS AND METHODS \\ Patient Selection}

From July to September 2004, patients with sickle cell disease (SCD) were consecutively recruited in a prospective study at the haematology outpatient clinic of the Yopougon Teaching Hospital, Abidjan, Ivory Coast. Patients included children and adults and were of both sexes. All SCD patients with diseases capable of causing microalbuminuria independently (e.g. hypertension, diabetes mellitus, cardiac diseases, primary renal diseases, malaria, HIV infection) were excluded, as were those with obesity and pregnancy. Patients with sickle cell trait and those who had experienced some sickling crisis within three months of the present study were also excluded.

\section{Methods}

In each patient, characteristics such as age, gender, ethnic group, weight, height, body mass index (BMI), blood pressure, type of hemoglobinopathy, glomerular filtration rate, microalbuminuria, complications related to the disease, and current treatment were collected.

Before the determination of microalbuminuria, dipsticks were used to test freshly voided morning urine to detect patients with any urinary tract infection as well as those with macroalbuminuria. Whenever urinary infection was suspected, a urine culture was performed.

Microalbuminuria was systematically assessed in patients without urinary infection or macroalbuminuria. The determination of microalbuminuria was performed by means of the HEMOCUE URINE ALBUMIN ANALYSER, batch $n^{\circ}$ 03G1286 manufactured for Hemocue by M-Pact Corporation, Hemocue ${ }^{\circledR}$, Hemocue AB, Angelholm, Sweden. The principle for the determination of microalbuminuria has been described elsewhere[4]. Microalbuminuria was considered when values between $30-300 \mathrm{mg} / \mathrm{l}$ were found at three consecutives concentrations.

The determination of the glomerular filtration rate (GFR) was performed using the following formula: The Cockcroft-Gault (CG) in adult patients: GFR $=[(140-$ Age $($ years $)) \times$ weight $(\mathrm{kg})] /$ serum creatine $(\mathrm{mg} / \mathrm{dl}) \times \mathrm{x}$ 72(x 0.85 if women $)(\mathrm{x} \mathrm{SC} / 1.73$ $\mathrm{m}^{2}$ ), the Schwartz formula in children : $0.55 \mathrm{x}$ length $(\mathrm{cm}) /$ serum creatine $(\mathrm{mg} / \mathrm{dl})$. Values of GFR more than $130 \mathrm{ml} / \mathrm{mn} / 1.73 \mathrm{~m}^{2}$ were considered to be elevated in females and $140 \mathrm{ml} / \mathrm{mn} / 1.73 \mathrm{~m}^{2}$ in males.

Blood pressure, weight and height were measured one time at the beginning of the recruitment process (BRP value) with the same tools for all the patients and compared to one or two former values already documented in the consultation progress notes. The BRP value is considered reliable when variation did not exceed $\pm 5 \%$ when compared to the values on the consultation sheet. When the variation exceeded $\pm 5 \%$, the mean of the two or three values was considered to be appropriate.

\section{Statistical Analysis}

Values are displayed as means +/- SD or in percentage. Comparison between groups was done using the chi square test or the Fisher exact test for qualitative parameters and the student $\mathrm{t}$ - test or the Mann Whitney test for quantitative parameters. Relationship between quantitative parameters and 


\section{Sickle Cell Glomerulopathy}

microalbuminuria was assessed by linear regression analysis while a forward selection logistic regression analysis was performed to identify predictors of microalbuminuria. Statistical significance was set at $\mathrm{P}$ value $<0.05$.

\section{RESULTS}

Seventy-five (75) patients who met the selection criteria were recruited over the three months study period. The characteristics of the study population are summarized in table 1 . The study population appeared young with a mean age of $16.58 \pm 9.08$ years and was predominantly male $(58.67 \%)$.

TABLE 1: Characteristics of the study population

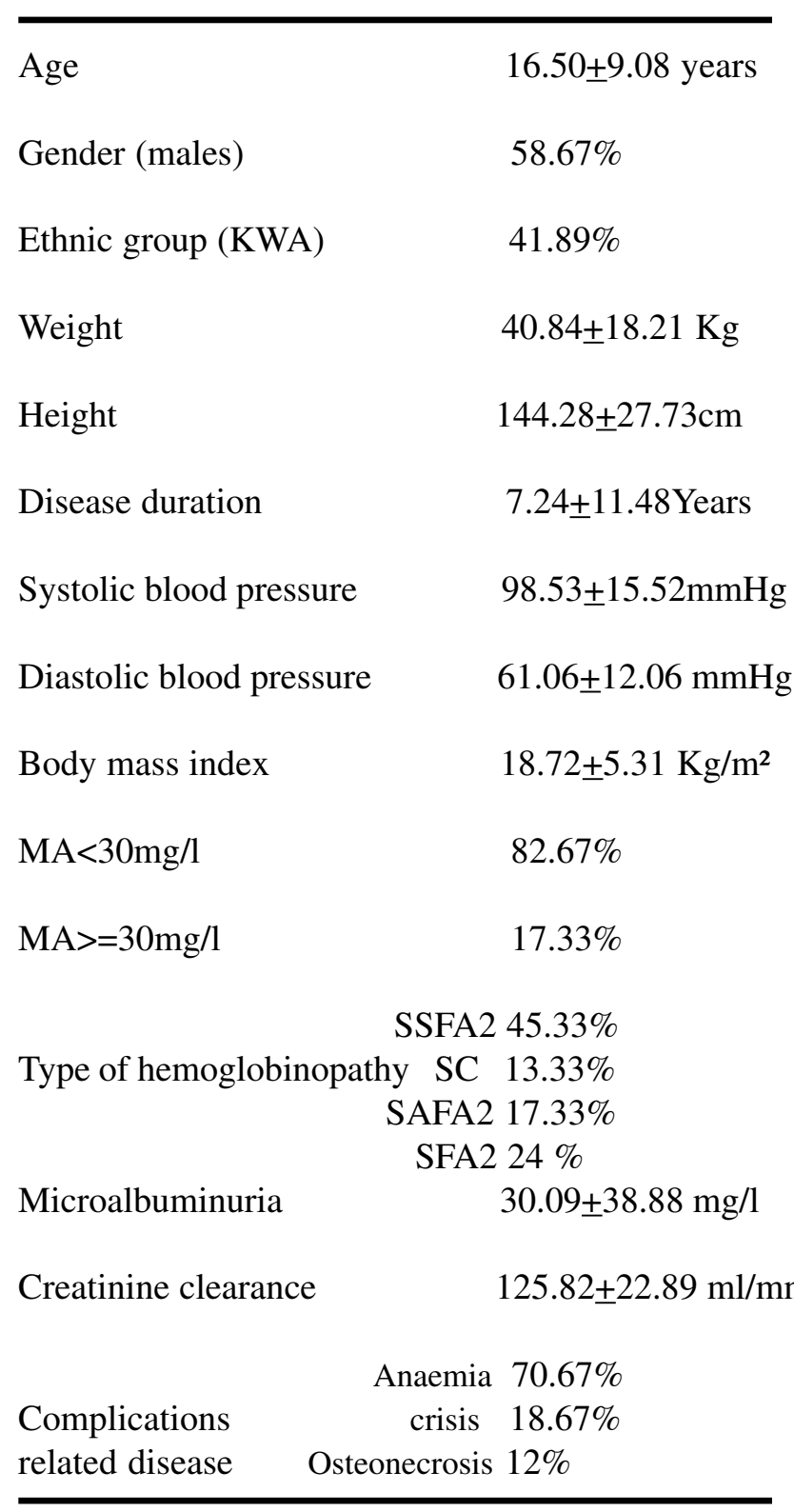

The SSFA2 hemoglobinopathy genotype was most common (45.33\%). $70.67 \%$ of the patients were anaemic. When patients were categorized according to microalbuminuria, 13 patients $(17.33 \%)$ presented with microalbuminuria with a mean of $96.11+/$ $-53.16 \mathrm{mg} / \mathrm{l}$ while 62 patients $(82.66 \%)$ were normoalbuminuric (NA) with a mean of $14.74+/-$ $10.33 \mathrm{mg} / \mathrm{l}$. The two groups were comparable with respect to age, weight, gender, ethnic group, blood pressure level, type of hemoglobinopathy, complications-related disease and treatment regimen (Table 2 and Table 3). By univariate analysis, GFR in the microalbuminuric group appeared significantly lower when compared to the normoalbuminuric group $(p<0.01)$. Patients with normoalbuminuria appeared significantly taller as compared to those with microalbuminuria $(\mathrm{p}=0.05)$ (Table 3 ). Anaemia was significantly more prevalent in the microalbuminuric group when compared to the normoalbuminuric group $(\mathrm{p}<0.05)$ (Table 2). By linear regression analysis no significant relationship was found between microalbuminuria and GFR ( $\mathrm{p}=0.87$ ). However on logistic regression analysis, low GFR appeared to promote significantly the development of microalbuminuria $(\mathrm{OR}=1.074) \mathrm{CI} 95 \%[1.020$ 1.136] $(\mathrm{p}<0.01)$, as did low height $(\mathrm{OR}=1.029 \mathrm{CI}$ 95\% [1.003 1.056] $)(\mathrm{p}<0.05)$ (Table 4). Anaemia has no effect on microalbuminuria on multivariate analysis. When age was considered, there was no difference in the prevalence of microalbuminuria between children and adults $(\mathrm{p}=0.31)$ and no relationship was found between GFR and microalbuminuria on multivariate analysis in either group.

\section{DISCUSSION}

In patients with $\mathrm{SCD}$, recurrence of vaso-occlusive crisis is common. This may lead to ischemia of the renal parenchyma with parallel reduction in the nephron number. There is a subsequent increase in the glomerular filtration rate that leads to glomerular hypertrophy, glomerulosclerosis and then to proteinuria. Theoretically, increase in the glomerular filtration rate may represent the predominant factor for microalbuminuria as it is the case in diabetic nephropathy[1]. However microalbuminuria in SCD 
TABLE 2 : Qualitatives variables

\begin{tabular}{|c|c|c|c|c|c|c|c|}
\hline & $\mathrm{M} / \mathrm{F}$ ratio & ethnic group & SSFA2 & $\mathrm{SC}$ & osteonecrosis & crisis & anaemia \\
\hline $\begin{array}{l}\text { MA } \\
(n=13)\end{array}$ & $1.16 / 1$ & $\begin{array}{l}30.77 \% \\
(\mathrm{KWA}) * *\end{array}$ & $53.85 \%$ & $15.38 \%$ & $15.38 \%$ & $30.76 \%$ & $92.30 \%$ \\
\hline $\begin{array}{l}\text { NA } \\
(n=62)\end{array}$ & $1.38 / 1$ & $\begin{array}{l}44.26 \% \\
\text { (KWA) }\end{array}$ & $43.55 \%$ & $24.19 \%$ & $16.12 \%$ & $16.12 \%$ & $66.13 \%$ \\
\hline
\end{tabular}

$P=\quad 0.77(N S) 0.17(N S) 0.19(N S) 0.24(N S) 0.67(N S) 0.21(N S) 0.04 *$

$* p<0.05 * *$ The KWA population represents the major ethnic group in IVORY COAST averaging $40 \%$ of the total population.

MA- Microalbuminuria

NA-Normoalbuminuria

TABLE 3: Quantitatives variables

\begin{tabular}{|c|c|c|c|c|c|c|c|}
\hline & $\begin{array}{l}\text { AGE } \\
\text { (Years) }\end{array}$ & $\begin{array}{c}\text { WEIGHT } \\
(\mathrm{Kg})\end{array}$ & $\begin{array}{l}\text { HEIGHT } \\
(\mathrm{CM})\end{array}$ & $\begin{array}{c}\text { SBP } \\
(\mathrm{mmHg})\end{array}$ & $\begin{array}{c}\text { DBP } \\
(\mathrm{mmHg})\end{array}$ & $\begin{array}{l}\text { CLEARANCE } \\
(\mathrm{ml} / \mathrm{mn})\end{array}$ & $\begin{array}{c}\text { BMI } \\
\left(\mathrm{Kg} / \mathrm{m}^{2}\right)\end{array}$ \\
\hline $\begin{array}{l}\text { MA } \\
(n=13)\end{array}$ & $\begin{array}{c}17.53+/- \\
14.22\end{array}$ & $\begin{array}{c}36+/- \\
23.75\end{array}$ & $\begin{array}{c}130.69+/- \\
33.32\end{array}$ & $\begin{array}{l}93.46+/- \\
21.25\end{array}$ & $\begin{array}{c}53.29+/- \\
14.69\end{array}$ & $\begin{array}{c}109.30 \\
+/- \\
16.68\end{array}$ & $\begin{array}{r}18.74 \\
+/- \\
5.47\end{array}$ \\
\hline $\begin{array}{l}\text { NA } \\
(n=62)\end{array}$ & $\begin{array}{c}16.29 \\
+/- \\
7.75\end{array}$ & $\begin{array}{l}41.85 \\
+/- \\
16.89\end{array}$ & $\begin{array}{c}147.12 \\
+/- \\
25.83\end{array}$ & $\begin{array}{c}99.59 \\
+/- \\
14.03\end{array}$ & $\begin{array}{c}61.45 \\
+/- \\
11.53\end{array}$ & $\begin{array}{c}129.29 \\
+/- \\
22.59\end{array}$ & $\begin{array}{c}18.61 \\
+/- \\
4.68\end{array}$ \\
\hline$P=$ & $0.65(N S)$ & $0.29(N S)$ & $0.05 *$ & $0.19(N S)$ & $0.54(N S)$ & $0.003 * *$ & $0.93(N S)$ \\
\hline \multicolumn{8}{|c|}{ 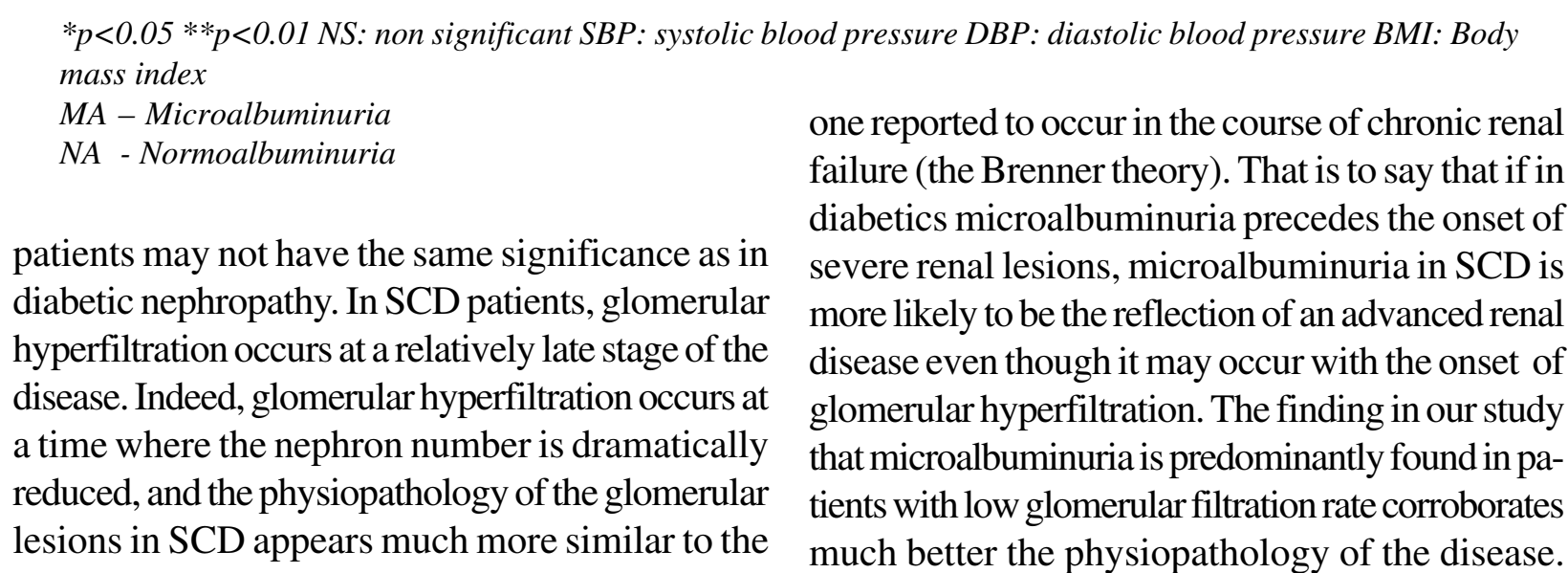 } \\
\hline
\end{tabular}


TABLE 4: Results of the forward selection logistic regression analysis

\begin{tabular}{lccccc}
\hline MA & Odds ratio & Std. Dev. & $\mathrm{Z}$ & $\mathrm{P}>|\mathrm{z}|$ & {$[95 \%$ conf. Interv. $]$} \\
\hline Low clearance & 1.076 & 0.03 & 4.97 & 0.007 & {$\left[\begin{array}{ll}1.020 & 1.136\end{array}\right]$} \\
Short height & 1.029 & 0.03 & 3.71 & 0.03 & {$\left[\begin{array}{ll}1.003 & 1.056\end{array}\right]$} \\
\hline
\end{tabular}

MA : microalbuminuria Std: standard deviation Conf.Interv. : Confidence interval

Moreover, microalbuminuria related to low glomerular filtration rate has also been demonstrated elsewhere in subjects with low birth weight [5]. Patients with microalbuminuria were significantly found to be more anaemic than the normoalbuminuric ones. This could mean that microalbuminuria may be related to a more depressed renal function which could then explain the high prevalence of anaemia in this group of patients. Several studies have indeed reported an inverse relationship between microalbuminuria and haemoglobin level $[6,7]$. Studies aimed at establishing a pathological correlation of both microalbuminuria and normoalbuminuria at autopsy as well as the level of erythropoietin in either groups are needed to confirm our findings.

However, no correlation has been established so far between microalbuminuria and glomerular hyperfiltration. The physiopathology of microalbuminuria in this setting may therefore be of different nature. Indeed microalbuminuria could reflect the renal manifestation of generalized vascular endothelial damage, which could underlie the link with recurrent vaso-occlusive crisis. Children and adults have displayed the same level of albuminuria in our study, like in other reports [8]. This may suggest that, together with the lack of effect of the disease duration on microalbuminuria, kidney damage in SCD may occur at any time in the lifespan of subjects depending on the severity of the disease and therefore on the intensity of the vascular damage. Microvascular complications are common in SCD patients. In diabetics as well as in the general population [1], MA is a strong predictor of cardiovascular mortality and morbidity. Whether microalbuminuria exhibits some prognostic value regarding cardiovascular mortality or morbidity in patients with SCD has never been clearly specified, though in a study [9] sickle cell haemoglobin has not been found to be a useful genetic marker for risk stratification in patients with cardiovascular disease.

Another factor that showed some relationship with microalbuminuria was height. It appeared to be inversely related to microalbuminuria in our study. This may be due to the classical relationship between body surface area (BSA) and creatinine clearance. The more the BSA the higher the creatinine clearance and the less microalbuminuria as reported in our study. However the fact that on multivariate analysis the two factors have expressed significance and no relationship was found between microalbuminuria and BMI, may suggest that short height might promote microalbuminuria through a different unknown mechanism.

\section{CONCLUSION}

The screening for microalbuminuria has proved to be of great benefit in patients with diabetic nephropathy as well as in the general population since it represents a predictor of renal dysfunction and the overall cardiovascular mortality. In patients with sickle cell disease, microalbuminuria appears to be a reflection of severe renal tissue damage as it is related to low glomerular filtration rate. Therefore the occurrence of microalbuminuria in the setting of SCD may prompt the implementation of urgent measures to halt progression of an already advanced disease.

\section{REFERENCES}

1. Mogensen CE, Keane WF and Bennett PH Prevention of diabetic renal disease with special reference to microalbuminuria. Lancet 1995; 346:1080-1084 
2. Katopodis KP, Elisaf SM and Pappas A et al Renal abnormalities in patients with sickle cellbeta thalassemia J Nephrol 1997; 10(3):163-167 3. Abbott, KC, Hypolite, IO and Agodoa, LY. Sickle cell nephropathy at end-stage renal disease in the United States: patient characteristics and survival Clin Nephrol 2002; 58(1): 9-15

4. Polkinghome, KR Detection and measurement of urinary protein Curr Opin Nephrol Hypertens. 2006; 15(6):625-630(review)

5. Keijzer-Veen MG, Schrevel M and Finken MJJ et al Microalbuminuria and lower glomerular filtration rate at young adult in subjects born very premature and after intrauterine growth retardation J Am Soc Nephrol 2005;16(9): 2762-2768
6. Mcburney PG, Hanevold CD and Hernandez CM. Risk factors for microalbuminuria in children with sickle cell anaemia J Pediatr Hematol Oncol 2002; 24(6):473-477

7. Alvarez O; Montane B and Lopez G. Early blood transfusions protect against microalbuminuria in children with sickle cell disease. Pediatr Blood Cancer 2006; 47(1):71-76

8. Aoki RY and Saad ST. Microalbuminuria in sickle cell disease Braz J Med Biol Res 1990; 23(4):1103-1106

9. Nwankwo MV, Bunker $\mathrm{CH}$, Ukoli FA et al Blood pressure and other cardiovascular disease risk factors in black adults with sickle cell trait or glucoe6-phosphate dehydrogenase deficiency. Gene Epidemiol 1990; 7(3):211-218 